\title{
Centrifuge model tests and large deformation analyses of a breakwater subject to combined effects of tsunami
}

\section{AUTHOR(S):}

Ueda, Kyohei; lai, Susumu; Tobita, Tetsuo

\section{CITATION:}

Ueda, Kyohei ...[et al]. Centrifuge model tests and large deformation analyses of a breakwater subject to combined effects of tsunami. Soil Dynamics and Earthquake Engineering 2016, 91: 294-303

\section{ISSUE DATE:}

2016-12

URL:

http://hdl.handle.net/2433/230139

\section{RIGHT:}

(c) 2016. This manuscript version is made available under the CC-BY-NC-ND 4.0 license

http://creativecommons.org/licenses/by-nc-nd/4.0/; The full-text file will be made open to the public on 01 December 2018 in accordance with publisher's 'Terms and Conditions for Self-Archiving'.; この論文は出版社版でありません。引 用の際には出版社版をご確認ご利用ください。; This is not the published version. Please cite only the published version. 
Title.

Centrifuge model tests and large deformation analyses of a breakwater subject to combined effects of tsunami

\section{Author names and affiliations.}

Kyohei Ueda ${ }^{1 *}$, Susumu Iai ${ }^{1}$, Tetsuo Tobita ${ }^{2}$

${ }^{1}$ Disaster Prevention Research Institute, Kyoto University, Gokasho, Uji, Kyoto, 611-0011 Japan

${ }^{2}$ Faculty of Environmental and Urban Engineering, Kansai University, 3-3-35 Yamate, Suita, Osaka, 564-8680 Japan

\section{*Corresponding author}

E-mail address: ueda.kyohei.2v@kyoto-u.ac.jp (Kyohei Ueda)

TEL: 81-774-38-4092

FAX: 81-774-38-4094 


\begin{abstract}
In this study, centrifuge model tests and effective stress analyses are performed on a tsunami-affected breakwater similar to those that were seriously damaged during the magnitude-9.0 East Japan Earthquake in 2011. The centrifuge model tests are performed at a scale of $1 / 200$ to simulate the failure of the breakwater. This study is a significant improvement on a previous one by the same authors. The centrifuge model tests now allow the seepage flow to be blocked as well as admitted, and the effective stress analyses are now performed based on the finite strain formulation in order to take large deformations into account instead of just the infinitesimal strain formulation that is applicable only to small displacements. Both the centrifuge model tests and the effective stress analyses demonstrate the important part played by the seepage of pore water in the failure of the rubble mound, in addition to the wave force of the tsunami action. In particular, it is shown that the breakwater damage of 2011 could have been prevented or at least mitigated by preventing seepage flow in the rubble mound.
\end{abstract}

Keywords: Centrifuge model test, Effective stress analysis, Breakwater, Tsunami, Strain space multiple mechanism model, Finite strain theory 


\section{Introduction}

An earthquake of magnitude 9.0, as measured by the Japan Meteorological Agency (JMA), occurred off the northeastern coast of Japan at 14:46 JST on March 11, 2011. The JMA named it "The 2011 off the Pacific coast of Tohoku Earthquake” (hereafter, the 2011 East Japan Earthquake). This is the greatest earthquake in magnitude to affect Japan since modern earthquake monitoring systems were established there.

The recorded heights of the tsunamis triggered by the earthquake were higher than 7.3 $\mathrm{m}$ at Soma, higher than $4.2 \mathrm{~m}$ at Oarai, and higher than $4.1 \mathrm{~m}$ at Kamaishi. Moreover, the impact of the tsunamis was the strongest since the existing design methodology was adopted for breakwaters. The existing design methodology of a breakwater is based on the limit equilibrium by considering the wave force acting on the lateral side and the additional pressure acting underneath the caisson [2], as shown in Fig. 1. The wave pressure on the lateral side is given as a linear distribution using the following values: the effective height above the still-water level, $\eta^{*}$; the intensities $p_{1}, p_{2}$, and $p_{3}$ of the wave pressure at the still-water level, the sea bottom, and the toe of the caisson, respectively; and the water depths $h, d$, and $h^{\prime}$ in front of the caisson, the crest of the mound, and the toe of the caisson, respectively. The uplift pressure acting at the bottom of the caisson is described by a triangular distribution with the pressure intensity $p_{u}$ at the front toe.

The most typical example of damage to a breakwater was the damage at the Kamaishi Harbor [3, 4]. The breakwater there was designed specifically to protect against the impact of a tsunami. It was constructed at the mouth of Kamaishi Harbor at a depth of 
$63 \mathrm{~m}$ or less and over a length of $990 \mathrm{~m}$ in the northern part and $670 \mathrm{~m}$ in the southern part with an opening of $300 \mathrm{~m}$ in between. However, the breakwater was devastated by the tsunami. This may have partially resulted from the inadequacies in the design procedure used at the time, but it was nevertheless characteristic of the serious damage that can be caused by a tsunami.

Figure 2 shows a typical cross section of the breakwater, which comprises a caisson and a rubble mound. Based on video data recorded from the coastline, the first arrival of the tsunami was at 15:24 (about 40 minutes after the earthquake occurred), and did not damage the breakwater.

However, there was a continuous overtopping of water at the top of the breakwater. The video data for 15:32, when the height of the tsunami had decreased, shows the breakwater to be seriously damaged. By 15:59, the damage had progressed further and many of the caissons fell into the harbor side from the rubble mound. The mound itself was seriously damaged to such an extent that about half of it was lost.

In order to investigate the primary mechanism for this type of breakwater failure due to a tsunami, we have performed a series of centrifuge model tests and effective stress analyses. As a straightforward extension of the existing design procedure shown in Fig. 1, a group of experts in hydrodynamics considered the primary mechanism of failure to have been erosion of the rubble mound by water flowing through the openings between the caissons [3-5], as shown in Fig. 3. In parallel to the efforts of that group, this study was performed with the aim of evaluating the effect of seepage flow through the rubble mound due to the water head difference caused by the tsunami in combination with the wave force action.

We previously reported preliminary results on the combined failure mechanism of a 
model breakwater subject to a simulated tsunami [1]. In that study, Silica No. 4 sand was used as the material for the rubble mound, in addition to Silica No. 1 sand, to reduce the effect of seepage flow into the rubble mound. Even so, seepage still existed and it was difficult to evaluate its effects or otherwise. In the previous study, both cases with Silica No. 1 and No. 4 sands resulted in the failure of the breakwater due to the seepage flow. The present study significantly improves the limitations of the previous one: (1) centrifuge model tests are newly performed with and without allowing seepage into the rubble mound by introducing artificial impermeable layer using a rubber membrane covering the surface of the rubble mound on the bay side for achieving no seepage flow condition, (2) effective stress analyses are performed based on the finite strain formulation in order to take large deformations into account. The previous study was based on the infinitesimal strain formulation that is applicable only to small displacements, even though the deformation observed in 2011 (particularly the movement of the caisson) was significant.

\section{Centrifuge model tests of a breakwater subject to a tsunami}

\subsection{Tsunami generator in centrifuge and model test conditions}

We used the geotechnical beam centrifuge at the Disaster Prevention Research Institute, Kyoto University (effective radius $2.5 \mathrm{~m}$ ) for the centrifuge model tests in this study. The equipment for simulating a tsunami in the centrifuge is shown in Fig. 4. Tsunami-like flow toward the caisson is generated by opening a valve at the bottom of a water tank. A BF diaphragm-type cylinder placed at the bottom of the right hand side of the box is utilized to remotely open the valve. The operation is done using compressed 
air from a portable air tank (about a mass of $10 \mathrm{~kg}$ ) that is attached to the centrifuge arm. Initially, an air pressure of $200 \mathrm{kPa}$ is applied to the BF cylinder to close the valve. Then, by applying an air pressure of $300 \mathrm{kPa}$ at the start of each experiment, a differential air pressure of $100 \mathrm{kPa}$ quickly opens the valve to generate tsunami-like flow. The levels of the air pressure were determined by trial and error basis under a given centrifugal acceleration. Overflowing water at the other end of the model (left in Fig. 4) is absorbed in a provisional storage pit to reduce the effect of wave reflection from the (left-hand) wall of the container.

The centrifuge model tests are performed in a 25 g centrifugal acceleration field using a 1/200-scale model of a 21-m-high caisson. We adopt a generalized scaling relation [6] that resolves the restriction of conventional scaling laws on the scale ratio due to the performance of the centrifuge. This makes it possible to carry out centrifuge model tests for large prototypes by setting a virtual $1 \mathrm{~g}$ field between the prototype and the centrifugal field even when the centrifuge capacity is limited. Table 1 lists the generalized scaling factors, combinations of the scaling factors for $1 \mathrm{~g}$ model tests, $\mu$, and centrifuge tests, $\eta$. The applicability of the generalized scaling law to dynamic soil behavior and soil-structure interaction problems has been verified in previous studies by means of a series of centrifuge model tests $[8,9]$.

When centrifuge model tests involve flow of fluid with gravity as the dominant force, the Froude number at model scale should be, in general, coincident with that at prototype scale as follow:

$$
F_{r}=\frac{V_{p}}{\sqrt{g_{p} L_{p}}}=\frac{V_{m}}{\sqrt{g_{m} L_{m}}}
$$

where $V_{i}$ is a flow velocity $(\mathrm{m} / \mathrm{s}), g_{i}$ is an acceleration due to gravity $\left(\mathrm{m} / \mathrm{s}^{2}\right)$, and $L_{i}$ 
is a length (m). The subscript $p$ and $m$ corresponds to the prototype and model scale, respectively. By applying the scaling factors for a $1 \mathrm{~g}$ field, $\mu$, and a centrifugal field, $\eta$, to Equation (1), the relation between $V_{p}$ and $V_{m}$ is given as

$$
V_{p}=\frac{\sqrt{g_{p} L_{p}}}{\sqrt{g_{m} L_{m}}} V_{m}=\frac{\sqrt{1 \times 1}}{\sqrt{\eta /(\mu \times \eta)}} V_{m}=\mu^{0.5} V_{m}
$$

In contrast, considering that a flow velocity, which differs from a particle velocity of which generalized scaling factor is $\mu^{0.75}$ shown in Table 1 , can be calculated by dividing length by time, $V_{p}$ is given in an alternative manner through the generalized scaling factors for length and time (see Table 1) as follows:

$$
V_{p}=\frac{L_{p}}{t_{p}}=\frac{(\mu \times \eta) \times L_{m}}{\left(\mu^{0.75} \times \eta\right) \times t_{m}}=\mu^{0.25} V_{m}
$$

where $t_{i}$ is a time (s). A comparison of Equations (2) and (3) indicates that the scaling factor for flow velocity (i.e., $\mu^{0.25}$ ) in the generalized scaling law is slightly different from that (i.e., $\mu^{0.5}$ ) based on the Froude law. In this study, the scaling factor for $1 \mathrm{~g}$ field is specified as $\mu=200 / 25=8$, which means that the velocity at prototype scale (i.e., $V_{p}$ ) scaled through the generalized scaling law becomes about 1.68 times less than the value based on the Froude law. As just described, it is difficult to simultaneously satisfy both the generalized scaling law and the Froude law in terms of velocity in centrifuge model tests for large prototypes when the centrifuge capacity is limited. In the present study, hence, the difference in the Froude number may be neglected by taking the following reasons into account: (1) the measured velocity (i.e., $2.4 \mathrm{~m} / \mathrm{s}$ ), estimated from the time difference between the arrival of the tsunami (i.e., the buildup 
of the excess pore water pressure) at PW4 and PW6 (shown in Fig. 13 later) and the distance between the sensors, in the centrifuge model tests has no significant difference from the actual tsunami velocity (e.g., $3.2 \mathrm{~m} / \mathrm{s}$ recorded at the Sendai-Shiogama Port during the 2011 East Japan Earthquake [10]), (2) the main aim of the model tests is to investigate the effect of seepage.

In the present study, the original sea level is set at $14 \mathrm{~m}$ below the top of the caisson, which allows overtopping to occur. Two cases were considered: the original one (Case 1) of a rubble mound with no membrane, and a comparison one (Case 2) of a membrane on top of the rubble mound on the exposed side to artificially prevent seepage. We use Silica No. 1 sand for the mound, the physical properties of which are as follows: the grain density is $2.62 \mathrm{~g} / \mathrm{cm}^{3}$, the maximum and minimum void ratios are 0.911 and 0.685 , respectively, the average grain size is $3.0 \mathrm{~mm}$, and the coefficient of uniformity is 1.53 . The membrane is made of natural latex and has a thickness of $0.3 \mathrm{~mm}$ and a Young's modulus of about $1.5 \times 10^{3} \mathrm{kPa}$. In centrifuge model tests for saturated ground, viscous water is often used as the pore fluid to achieve equivalence of the model and the prototype in terms of permeability when the same ground material as that in the prototype is used. However, pure water is used here because Silica No. 1 sand is used to take the scale effect into account through the scaling law [11]. The average sand-grain size $(3 \mathrm{~mm}$ ) is about $1 / 200$ th that of the prototype rubble $(200-800 \mathrm{~mm})$. The rubble mound model is formed using water pluviation at a relative density of $60 \%$.

The model is instrumented with six pore pressure transducers (SSK Co., Ltd.; P306-A), which are $6 \mathrm{~mm}$ in height and $8 \mathrm{~mm}$ in diameter, as shown in Fig. 4. A high-speed camera (Nac Image Technology, Inc.; MEMRECAMfx RX-6G) is installed on the centrifuge arm to take a snapshot of the breakwater behavior through the front side of 
the container. The sampling intervals are $1 / 5000 \mathrm{~s}$ and 1/500 $\mathrm{s}$ for the pore pressure transducers and the high-speed camera, respectively.

\subsection{Centrifuge test results}

Figure 5 shows the results of the centrifuge tests for Cases 1 and 2 with respect to the deformation. As described earlier, Case 1 is performed in order to simulate the prototype conditions. As shown in Fig. 5(A-2), the caisson remains standing without deformation when the tsunami hits it at a water-level difference of $14 \mathrm{~m}$. At the same time, bubbles appear on the bay (left) side and continue to appear afterward (A-3), indicating that water is seeping through the rubble mound. After a moment (A-4), the rubble mound gradually deforms in a bearing capacity failure mode with inclined load together with the caisson toward the direction of the tsunami wave force. The caisson eventually falls from the rubble mound, which exhibits a residual failure mode that resembles the classic circular failure one.

These failure modes of the caisson and the rubble mound are consistent with those investigated and identified at Kamaishi Harbor after the 2011 East Japan Earthquake. This suggests that tsunamis cause breakwater failures by the combined effects of seepage flow and wave action. However, erosion progressing from the harbor side would produce a similar failure mode. Hence, the failure mechanism has to be studied further by performing effective stress analysis as described later.

Case 2 provides a comparison with Case 1 by using a rubber membrane (thick red line in Fig. 4) on the side of the oncoming wave to artificially reduce the seepage into the rubble mound. The effect of this is confirmed by the pore pressure measurements shown in Fig. 6, and the fact that no bubbles with seepage flow are ejected from the landward 
bottom corner of the caisson (Fig. 5(B-2) and (B-3)) in Case 2, unlike Case 1, when the tsunami hits the caisson. Whereas the caisson is more inclined and shifted towards the landward direction, as shown in Fig. 5(A-3), for Case 1, the caisson and the rubble mound continue to withstand the oncoming wave even though overtopping occurs, as shown in Fig. 5(B-4) and (B-5), without seepage for Case 2.

The excess pore water pressure measured in the rubble mound at the bottom of the caisson is shown in Fig. 6. For Case 1 (seepage), the pressure rises steadily for $\sim 60 \mathrm{~s}$ before spikes appear in the data, whereas there are no substantial changes for Case 2 (no seepage). We postulate that the pressure spikes in Case 1 are caused by the waves that accompany the sliding and turnover of the caisson as shown in Fig. 5(A-2) through (A-5). The relatively small pressure changes in Case 2 may be due to overtopping or some water leaking through the membrane.

\section{Finite strain formulation of strain space multiple mechanism model}

For an effective stress analysis of a breakwater subject to seepage and wave action, we use the strain space multiple mechanism model with a cocktail glass model [12].

The two-dimensional infinitesimal strain formulation of the model for sand relates the macroscopic effective stress tensor $\boldsymbol{\sigma}^{\prime}$ and the strain tensor $\boldsymbol{\varepsilon}$ by

$$
\boldsymbol{\sigma}^{\prime}=-p \mathbf{I}+\int_{0}^{\pi} q\langle\mathbf{t} \otimes \mathbf{n}\rangle \mathrm{d} \omega,\langle\mathbf{t} \otimes \mathbf{n}\rangle=\mathbf{t} \otimes \mathbf{n}+\mathbf{n} \otimes \mathbf{t}
$$

Here, $\mathbf{I}$ is the second-order identity tensor, and $\mathbf{n}$ and $\mathbf{t}$ are the direction vectors normal and tangential, respectively, to the particle contacts within the granular material. The scalars $p$ and $q$ are functions with history of the volumetric strain $\varepsilon$, the volumetric 
strain due to dilatancy $\varepsilon_{\mathrm{d}}$, and the virtual simple shear strain $\gamma$. They are given by

$$
p=p\left(\varepsilon^{\prime}\right), q=q(\gamma)
$$

where

$$
\varepsilon^{\prime}=\varepsilon-\varepsilon_{\mathrm{d}}, \quad \varepsilon=\mathbf{I}: \boldsymbol{\varepsilon}, \gamma=\langle\mathbf{t} \otimes \mathbf{n}\rangle: \boldsymbol{\varepsilon}
$$

In particular, $q$ is a hysteretic hyperbolic function and approximates the hysteretic hyperbolic curve of the macroscopic shear stress and shear strain in cyclic simple shear. In the finite strain formulation of the strain space multiple mechanism model, the unit vector $\mathbf{N}$ in the direction of the branch between two particles in contact with each other and the unit vector $\mathbf{T}$ normal to $\mathbf{N}$ are defined in the reference (or initial) configuration of the material. These vectors are assumed to change direction and magnitude into $\mathbf{n}$ and $\mathbf{t}$ in the current configuration through the deformation gradient $\mathbf{F}$ as follows:

$$
\mathbf{n}=\mathbf{F N}, \mathbf{t}=\mathbf{F T}, \mathbf{F}=\frac{\partial \mathbf{x}}{\partial \mathbf{X}}
$$

where the motion of the material transforms the reference position vector $\mathbf{X}$ defined on the material in the initial configuration to the current position vector $\mathbf{x}$ as shown in Fig. 7.

In the finite strain formulation in the reference configuration, the second Piola-Kirchhoff effective stress $\mathbf{S}^{\prime}$ is used, which is given by the Cauchy effective stress $\boldsymbol{\sigma}^{\prime}$ defined in the current configuration through

$$
\mathbf{S}^{\prime}=\mathbf{F}^{-1} J \boldsymbol{\sigma}^{\prime} \mathbf{F}^{-\mathrm{T}}, J=\operatorname{det} \mathbf{F}
$$

The infinitesimal strain formulation of Equations (4) and (5) is modified by applying the well-established approach for compressible materials [13], in which the deformation is 
decomposed into volumetric and isochoric parts. By applying this approach to the strain space multiple mechanism model, the second Piola-Kirchhoff effective stress is decomposed as follows:

$$
\mathbf{S}^{\prime}=\mathbf{S}_{p}^{\prime}+\mathbf{S}_{q}^{\prime}=-J p \mathbf{C}^{-1}+J^{-1},: \overline{\mathbf{S}}
$$

where

$$
\overline{\mathbf{S}}=\int_{0}^{\pi} J q\langle\mathbf{T} \otimes \mathbf{N}\rangle \mathrm{d} \omega, \mathbf{C}=\mathbf{F}^{\mathrm{T}} \mathbf{F}
$$

The fourth-order tensor , called the projection tensor, extracts the isochoric component of the second order tensor $\overline{\mathbf{S}}$ in the reference configuration, being defined in two dimensions by using the fourth-order identity tensor · as follows:

$$
\text { 、 } \cdot-\frac{1}{2} \mathbf{C}^{-1} \otimes \mathbf{C}
$$

The integrated form of the constitutive equation (i.e., direct stress-strain relationship) in the reference configuration is derived by relating the macroscopic strain tensor to the macroscopic effective stress through the structure defined by Equations (9) and (11). The macroscopic strain tensor defined in the reference configuration is called the Green-Lagrange strain tensor, defined as

$$
\mathbf{E}=\frac{1}{2}\left(\mathbf{F}^{\mathrm{T}} \mathbf{F}-\mathbf{I}\right)
$$

Using this strain tensor, the volumetric strain $\varepsilon$ and the virtual simple shear strains $\gamma$ appearing in Equation (5) in the context of the finite strain formulation are given by

$$
\varepsilon=\ln J=\frac{1}{2} \ln [\operatorname{det}(2 \mathbf{E}+\mathbf{I})], \gamma=\langle\mathbf{T} \otimes \mathbf{N}\rangle: \mathbf{E}
$$

The finite strain formulation given by Equations (9) through (13) is for the reference configuration and forms the basis for the total Lagrangian (TL) formulation. The 
push-forward operation of these equations results in the basis for the updated Lagrangian (UL) formulation written in terms of the current direction vectors $\mathbf{n}$ and $\mathbf{t}$ defined in Equation (7). See [14] and [15] for further details.

\section{Effective stress large deformation analyses of a breakwater subject to a tsunami}

\subsection{Load conditions for simulating the tsunami}

The effective stress large deformation analysis of a breakwater is performed for prototype scaled from the centrifuge model through the generalized scaling law, including a 21-m-high caisson. Instead of the numerical modeling at prototype scale, a numerical analysis of the centrifuge model at model scale can be carried out using 1/200 the size of the finite element mesh shown in Fig. 8. In that case, the acceleration due to gravity and tsunami wave force should be given as a value at model scale as described in Appendix, and the analytical results can then be scaled to prototype scale using the scaling factors (e.g., $\mu^{1.5} \eta$ for displacement, $\mu$ for pore pressure) listed in Table 1. As shown in Fig. A.1, the scaled results are identical to the results obtained by the numerical analysis of the centrifuge model tests at prototype scale. This is why only the numerical modeling at prototype scale is described hereinafter in detail.

As shown in Fig. 8, joint elements are specified at the bottom of the caisson to allow sliding and separation between the caisson and the rubble mound. The friction angle of the element is set to 31 degrees based on previous work [16]. After a static gravity analysis to set the initial conditions for the dynamic tsunami analysis, the tsunami wave force (described below) is applied to the caisson as an equivalent static distributed force as shown in Fig. 9. In order to analyze the effect of seepage due to sea-level difference, 
excess pore water pressure is applied at the rubble mound according to the height $a_{f}$ of the tsunami wave, which is assumed to be $11 \mathrm{~m}$ above the sea level based on the results of the centrifuge model tests. The external force due to the sea-level difference is also simulated by an equivalent lateral static force on the caisson.

The distribution and magnitude of the wave force due to the tsunami that we adopt for the analysis (Fig. 9) were as proposed by Tanimoto et al. [17] and as adopted in the breakwater design (Fig. 1). By using the wave height $a_{f}$, the effective height $\eta^{*}$ above still-water level is given by

$$
\eta^{*}=3.0 a_{f}
$$

In the proposal, the wave pressure $p_{1}$ at still-water level is assumed to be equal to $p_{3}$ at the toe of the caisson and is estimated as

$$
p_{1}=2.2 \rho_{w} g a_{f}
$$

where $\rho_{w}$ is the density of seawater $\left(\mathrm{t} / \mathrm{m}^{3}\right)$ and $g$ is the acceleration due to gravity $\left(\mathrm{m} / \mathrm{s}^{2}\right)$. The uplift pressure acting on the bottom of the caisson shown in Fig. 1 is not specified as a distributed load because the effect is automatically included in the effective stress analysis allowing seepage flow. As shown in Fig. 8, the water depth $d$ at the crest of the mound is equal to that at the toe of the caisson, i.e., $h '$. In the analysis, the wave force and the excess pore water pressures are increased from zero to the specified level for a duration of $40 \mathrm{~s}(t=20-60 \mathrm{~s})$ in the prototype in order to approximate the measured oncoming wave effects in the centrifuge model tests as shown in Fig. 6. The analyses are continued for a further $10 \mathrm{~s}(t=60-70 \mathrm{~s})$.

The effective stress analyses are performed for Cases 1 through 3 under the load conditions shown in Fig. 9 using the constitutive model for the rubble mound as 
described in Chapter 3. The material parameters listed in Table 2 were determined based on laboratory tests (i.e., hollow cylinder torsional shear tests and constant head permeability tests) for Silica No.1 sand.

In the following sections, we present only the numerical results of the large deformation analysis based on the TL formulation. This is because the UL formulation has been confirmed previously to be numerically equivalent to the TL one (e.g., [18]).

\subsection{Results of the effective stress large deformation analyses}

Figure 10(a) shows the residual deformation of the breakwater due to the combined effect of the tsunami wave force on the caisson and the seepage flow in the rubble mound (Case 1). The tilting of the caisson is associated with a significant deformation of the rubble mound. This mode of failure is consistent with that observed in the centrifuge model tests. In comparison, the deformation of the breakwater due to the tsunami wave force alone is considerably smaller as shown in Fig. 10(b). These results are consistent with the results of the centrifuge model tests shown in Fig. 5. They indicate that the primary mechanism of breakwater failure due to a tsunami is a combined failure mechanism involving the tsunami wave force and the seepage flow in the rubble mound caused by the water-level difference associated with the tsunami.

In addition, Fig. 10(c) shows the deformation of the breakwater due to the seepage flow alone (Case 3). In this case, the deformation of the breakwater is negligibly small. This again points to the primary failure mechanism being the the combined effect of wave action and seepage flow in the rubble mound.

In order to confirm the applicability of the effective stress analyses based on the large deformation formulation, the computed lateral displacement at the top of the breakwater 
(Fig. 12) and the excess pore water pressures in the rubble mound (Figs. 13, 14) are compared with the measured values. The lateral displacement is measured from photographs (Fig. 5) for several different times because there was no displacement transducer on the top of the breakwater during the centrifuge model tests. The locations of the measured and computed excess pore water pressures are depicted in Fig. 11. As shown in Fig. 13 for Case 1 (i.e., allowing seepage flow in the rubble mound besides wave force on the caisson), the computed results successfully capture the buildup response of the measured excess pore water pressure due to seepage in the rubble mound, in particular at PW1 and PW4. The computed displacement at the top of the caisson for Case 1 also well captures the timing of threshold for inducing the lateral displacement at about $50 \mathrm{~s}$ although the amount of increase is undervalued relative to the measurement as shown in Fig. 12. For Case 2 without seepage, no significant increase in the computed excess pore water pressure is recognized in Fig. 14, as is the case with the centrifuge model tests. The computed and measured lateral displacements at the top of the caisson in Case 2 are smaller than those in Case 1 (Fig. 12). These results indicate that the effective stress analyses performed in this study represent the seepage flow in the rubble mound reasonably well in relation to the excess pore water pressure.

Figures 15 and 16 show the computed maximum shear strain distribution for Cases 1 and 2, respectively. The maximum shear strain $\gamma_{\max }$ in the TL formulation is calculated using

$$
\gamma_{\max }=\sqrt{\left(E_{11}-E_{22}\right)^{2}+E_{12}^{2}}
$$

where $E_{11}, E_{22}$, and $E_{12}$ are the components of the Green-Lagrange strain tensor $\mathbf{E}$ 
(i.e., Equation (12)) in the reference configuration. As shown in Figs. 15(a) and 16(a), no significant strain is generated at the middle of the load increasing phase ( $t=40 \mathrm{~s})$. Then, at the end of this phase ( $t=60 \mathrm{~s}$ ), Fig. 15(b) for Case 1 shows two shear bands due to strain evolution (about 40-50 \%), which spread vertically and obliquely from the lower left and right corners of the caisson, respectively. For Case 2, however, the magnitude of the induced strain in Fig. 16(b) is negligibly small. This is because the seepage effect is ignored and the excess pore water pressure in the rubble mound does not increase, as shown in Fig. 14. Finally, at the end of the analysis ( $t=70 \mathrm{~s}$ ), a maximum shear strain $\geq 100 \%$ is generated and the shear bands become clearer. This enhances the tilting of the caisson for Case 1, as shown in Fig. 15(c). For Case 2, we see two shear bands that are due to the wave force alone (i.e., no seepage flow), although these are not as clear as the one for Case 1.

\subsection{Effect of tsunami height on lateral displacement of caisson}

In this section, we use effective stress large deformation analyses to study the effect of tsunami height (i.e., the difference in water levels in front of and behind the breakwater) on the lateral displacement of the caisson. The analytical condition is the same as the one described in Section 4.1, except for the water-level difference. The analyses are performed for Case 1 (seepage + wave force) and Case 2 (wave force only) by changing the water level in front of the caisson (i.e., the ocean side) while keeping the one behind (i.e., the bayside) constant.

Figure 17 shows the relationship between the water-level difference and the lateral displacement of the caisson top. Solid circles represent transition points at which the slope of the graph changes suddenly. For Case 1, the lateral displacement increases 
rapidly as the water-level difference becomes larger than $9.3 \mathrm{~m}$. However, a water-level difference larger than $10.5 \mathrm{~m}$ is required to induce the increase in the lateral displacement for Case 2 under wave force only. We consider the difference between Cases 1 and 2 (i.e., $1.2 \mathrm{~m}$ ) to be caused by the presence or absence of the seepage flow.

\section{Conclusions}

In this study, centrifuge model tests and effective stress analyses were performed on a tsunami-affected breakwater similar to those that were seriously damaged during the magnitude-9.0 East Japan Earthquake in 2011. The centrifuge model tests at a scale of $1 / 200$ and the effective stress analyses based on the large deformation formulation all demonstrated the important part played by the seepage of pore water in the failure of the rubble mound, in addition to the more obvious wave force of the tsunami. In particular, the new centrifuge tests showed that covering the oncoming-wave side of the rubble mound with a rubber membrane to prevent seepage could either prevent or at least limit the damage done to the breakwater.

\section{Appendix}

As a comparison to the effective stress large deformation analysis of the breakwater at prototype scale, another analysis is performed at model scale using the finite element mesh, of which size is $1 / 200$ of the prototype shown in Fig. 8, for Case 1. The height and width of the caisson at model scale are $105 \mathrm{~mm}$ and $65 \mathrm{~mm}$, respectively (see Fig. 4). During the static gravity analysis to set the initial conditions, the acceleration due to 
gravity at prototype scale (i.e., in 1 g gravitational field) should be modified to model scale under the centrifugal acceleration (i.e., 25 g) considering the generalized scaling factor for acceleration (i.e., $1 / \eta$ ) listed in Table 1 . After the static analysis, the tsunami wave force is applied to the caisson as a distributed load by using Equation (15) during the dynamic tsunami analysis. In the equation, the wave height $a_{f}$ should be specified as a value at model scale by applying the generalized scaling factor for displacement (i.e., $\eta^{1.5} \eta$ ), in addition to the modification of the acceleration due to gravity. Furthermore, the model parameters listed in Table 2 have to be changed to model scale through the generalized scaling law (e.g., $G_{\mathrm{ma}}=2.17 \times 10^{4} \mathrm{kPa}$ at $p_{\mathrm{a}}=98 \mathrm{kPa}$ and $c_{\mathrm{a}}=2.5 \mathrm{kPa}$ are used at model scale).

The numerical results obtained using the geometric dimension (i.e., the mesh size) at model scale can then be scaled to prototype scale, using the generalized scaling factors listed in Table 1 , in order to compare the scaled results with those obtained by the numerical analysis at prototype scale. Figure A.1(a), which is a reproduction of Fig. 10(a), shows the residual deformation of the breakwater obtained using the geometric dimension at prototype scale (i.e., the finite element mesh in Fig. 8). In comparison, the deformation of the breakwater obtained using the geometric dimension at model scale (i.e., 1/200th of the prototype mesh) is depicted in Fig. A.1(b) and (c). Because the deformation in Fig. A.1(b) is represented as model scale, the computed lateral displacement at the top of the breakwater is significantly small compared to that in Fig. A.1(a). By contrast, the deformation in Fig. A.1(c) is represented as prototype scale by applying the scaling factor for displacement (i.e., $\mu^{1.5} \eta$ ) to the result shown in Fig. A.1(b). A comparison of Fig. A.1(c) with Fig. A.1(a) suggests that we can obtain the 
identical results, including the lateral displacement at the top of the breakwater, with those obtained using the prototype geometric dimension by considering the generalized scaling law.

\section{References}

[1] Iai S. Combined Failure Mechanism of a Breakwater Subject to Tsunami during 2011 East Japan Earthquake. In: Ansal A, Sakr M (Eds.), Perspectives on Earthquake Geotechnical Engineering in Honour of Prof. Kenji Ishihara. Springer 2015; 177-186.

[2] Technical Standards and Commentaries for Port and Harbour Facilities in Japan. The Overseas Coastal Area Development Institute of Japan 2009.

[3] Arikawa T, Sato M, Shimosako K, Hasegawa I, Yeom GS, Tomita T. Failure Mechanism of Kamaishi Breakwater due to the Great East Japan Earthquake Tsunami. Proceedings of 33rd Conference on Coastal Engineering 2012; structures.16.

[4] Ishikawa N, Arikawa T, Beppu M, Tatesawa H. Collapse mechanism of sea wall protective structure by huge tsunami. In: Hao, Li (Eds.), Advances in Protective Structures Research. Taylor and Francis 2012; 253-279.

[5] Port and Airport Research Institute. Study of the Failure Mechanism of Tsunami Breakwater at Kamaishi Port due to the Great East Japan Earthquake Tsunami [Online]. Available: http://www.pari.go.jp/files/items/3544/File/20110401-3.pdf [Accessed 10 February 2016] (in Japanese).

[6] Iai S, Tobita T, Nakahara T. Generalized scaling relations for dynamic centrifuge tests. Géotechnique 2005; 55(5): 355-362.

[7] Iai S. Similitude for shaking table tests on soil-structure-fluid model in $1 \mathrm{~g}$ gravitational field. Soils and Foundations 1989; 29(1): 105-118.

[8] Tobita T, Iai S, von der Tann L, Yaoi Y. Application of the generalised scaling law to saturated ground. International Journal of Physical Modelling in Geotechnics 2011; 11(4): 138-155.

[9] Wada T, Ueda K, Iai S, Tobita T. Applicability of the generalized scaling law to the dynamic behavior of pile-inclined ground system in centrifuge mode tests. Proceedings of 1st International Conference on Natural Hazards and Infrastructure 2016; Paper No. 61.

[10] Kawai H, Satoh M, Kawaguchi K, Seki K. Characteristics of the 2011 off the Pacific Coast of Tohoku Earthquake Tsunami. Report of the Port and Airport Research Institute 2011; 50(4): 3-63 (in Japanese).

[11] Fuglsang LD, Ovesen NK. The application of the theory of modelling to centrifuge studies. Centrifuge in Soil Mechanics. Balkema 1988: 119-138.

[12] Iai S, Tobita T, Ozutsumi O, Ueda K. Dilatancy of granular materials in a strain space multiple mechanism model. International Journal for Numerical and Analytical Methods in Geomechanics 2011; 35(3): 360-392.

[13] Holzapfel GA. Nonlinear Solid Mechanics: A Continuum Approach for Engineering. John Wiley \& Sons Ltd 2000.

[14] Ueda K. Finite Strain Formulation of a Strain Space Multiple Mechanism Model for Granular Materials and Its Application, Doctor's Dissertation, Kyoto University, 2009 (in Japanese).

[15] Iai S, Ueda K, Tobita T, Ozutsumi O. Finite Strain Formulation of a Strain Space Multiple Mechanism Model for Granular Materials. International Journal for Numerical and Analytical Methods in Geomechanics 2013; 37(9): 1189-1212.

[16] Iai S, Ichii K, Liu H, Morita T. Effective stress analyses of port structures. Soils and Foundations 1998; Special Issue on Geotechnical Aspects of the January 17, 1995 Hyogoken-Nambu Eathquake, No. 2: 97-114.

[17] Tanimoto K, Tsuruya K, Nakano S. Tsunami wave force and failure mechanism of bulkhead due 
to Tsunami during 1983 Nihonkai-Chubu earthquake. In: Proc. 31th Research Conference on Coastal Engineering 1984; 257-261 (in Japanese).

[18] Ueda K, Iai S, Ozutsumi O. Finite deformation analysis of dynamic behavior of embankment on liquefiable sand deposit considering pore water flow and migration. Proceedings of The 6th International Conference on Earthquake Geotechnical Engineering (in Christchurch, New Zealand) 2015; Paper No. 215. 